\title{
Briefly about Anticancer Properties of Statins
}

\section{Radostina Alexandrova*1, Desislav Dinev ${ }^{1}$, Milena Glavcheva ${ }^{1}$, Jula Danova ${ }^{1,2}$, Gunay Yetik-Anacak ${ }^{3}$, Jelena Krasilnikova ${ }^{4}$ and Crtomir Podlipnik ${ }^{5}$}

${ }^{1}$ Institute of Experimental Morphology, Pathology and Anthropology with Museum, Bulgarian Academy of Sciences, Sofia, Bulgaria

${ }^{2}$ Medical Faculty, Sofia University “St. Kliment Ohridski”, Sofia, Bulgaria

${ }^{3}$ Department of Pharmacology, Faculty of Pharmacy, Ege University, Bornova-Izmir, Turkey

${ }^{4}$ Rigas Stradin University, Riga, Latvia

${ }^{5}$ Faculty of Chemistry and Chemical Technology, University of Lubljana, Lubljana, Slovenia

*Corresponding author: Radostina Alexandrova, Institute of Experimental Morphology, Pathology and Anthropology with

Museum, Bulgarian Academy of Sciences, Bulgaria

\begin{abstract}
ARTICLE INFO
Received: 門 April 12, 2019

Published: 幽 April 22, 2019

Citation: Alexandrova R, Dinev D, Glavcheva M, Danova J, Yetik-Anacak G et al. Briefly about Anticancer Properties of Statins. Biomed J Sci \& Tech Res 17(2)-2019. BJSTR. MS.ID.002975.

ABSTRACT

Statins (3-Hydroxy-3-Methylglutaryl-CoA Reductase Inhibitors) have been clinically used for the treatment of dyslipidemia / hypercholesterolemia for almost 40 years. This class of medications represents some of the most frequently prescribed drugs in the world and are the main players in pharmacologic primary and secondary prevention of atherosclerotic cardiovascular disease. Statins have gained much recent attention due to their antitumor effects. This mini review summarizes data about some potential anticancer properties of statins, putative mechanisms of their antitumor activity, and the challenges that have to be overcome in order to facilitate the introduction of these drugs in oncology practice.
\end{abstract}

Keywords: 3-Hydroxy-3-Methylglutaryl-CoA (HMG-CoA) Reductase Inhibitors; Statins; Cancer; Antitumor Activity

\section{Introduction}

Statins are potent competitive inhibitors of 3-Hydroxy-3Methylglutaryl-CoA (HMG-CoA) reductase, a rate-limiting enzyme in the mevalonate pathway (cholesterol synthesis or isoprenoid pathway) by which HMG-CoA is converted to mevalonate. Mevalonic acid is the precursor in the biosynthesis of isoprenoid molecules such as cholesterol, dolichol, ubiquinone, Farnesyl Pyrophosphate (FPP) and Geranyl Geranyl Pyrophosphate (GGPP) $[1,2]$. Statins were initially identified as secondary metabolites of fungi [3]. The discovery of the first HMG-CoA reductase inhibitor (ML-236A) obtained from Penicillium citrinum was reported in 1976 [1,4]. As of 2013, there are seven statin drugs available: Atorvastatin (Lipitor and Torvast), Fluvastatin (Lescol), Lovastatin (Mevacor, Altocor, Altoprev), Pitavastatin (Livalo, Pitava), Pravastatin (Pravachol, Selektine, Lipostat), Rosuvastatin (Crestor), and Simvastatin:(Zocor,Lipex) (http://www.fda.gov/Drugs/ DrugSafety/InformationbyDrugClass/ucm294358.htm). The pleiotropic effects of statins are well known. In addition to their potential to modify dyslipidemia (the most common application for this class of medications), statins affect some other key biological processes including inflammation, nitric oxide synthesis, coagulation cascade, etc. They have been recognized as potential candidates for the prevention / treatment of neurologic diseases, such as Alzheimer's disease, Parkinson's disease, and multiple sclerosis [5].

\section{Statins and Cardiovascular Diseases}

Cardiovascular Diseases (CVD) accounts for $>17$ million deaths globally every year, and this number is predicted to rise to $>23$ million by 2030 [6]. Dyslipidemia has been shown to be a strong risk factor for CVD [7]. Statins are recognized as the most effective class of drugs for the treatment of lipid disorders. Randomized controlled trials and meta-analyses show the ability of statins to produce a significant reduction of incidental myocardial infarction, stroke, and death from atherosclerotic CVD in the patients. With more than 200 million people worldwide taking these drugs, 
nowadays, statins are the most powerful pharmacologic weapon for the primary and secondary prevention of atherosclerotic CVD [8-11].

\section{Safety}

Statins have been documented to be well tolerated, and the risk of adverse symptoms is insignificant compared to the benefits. Toxicity is limited as HMG-CoA, the immediate precursor before the block, is water soluble and can be metabolised via alternative metabolic pathways, thus, preventing accumulation [12]. Muscleassociated symptoms including fatigue, weakness, and pain (possibly accompanied by elevated serum creatine kinase activity) are associated with statin use. Myalgia is the most common side effect of these medications (with documented rates of 1-10\%) but is often mild and for most patients does not limit treatment In others, reducing the dose or changing the medication may help. The withdrawal of the statin leads to resolution. Rhabdomyolysis is the most serious adverse effect of statins that affects only a tiny proportion of statin users (less than $0.1 \%$ ).

Rhabdomyolysis may result in acute renal failure, disseminated intravascular coagulation, and death. Multiple risk factors for statin-induced myopathy have been established, including both patient-related (age, genetics, co-morbidities) and drug-related (statin metabolism via the CYP system, drug-drug interactions, and statin drug transport) factors. The most common risks among them are hypothyroidism, drug-drug interactions, and alcohol abuse [12-16]. Cerivastatin (Baycol, Lipobay) was withdrawn from the market in 2001 due to fatal rhabdomyolysis and kidney failure [17]. Statins have been found to exert a diabetogenic action, and the risk appears to increase among patients receiving higher doses $[18,19]$. Pitavastatin has not been associated with increased risk of diabetes [20].

\section{Anticancer Activity of Statins}

The anticancer properties of statins were reported in early 1990s. Their ability to express antiproliferative and proapoptotic effects have been documented in a wide range of cancer cell lines and animal tumor models $[21,22]$.

The antitumor activity of statins can be related to various mechanisms of action some of which are listed below:

a) FPP and GGPP (by-products of mevalonate pathway) are essential substrates for posttranslational modification of rat sarcoma viral oncogene homologue (RAS) and RAS Homologue (RHO) - GTPases that are involved in the regulation of important biological processes in all eukaryotic cells and are associated with cell growth, proliferation, migration, and survival $[23,24]$.

b) Ability of statins to synchronize tumor cells by blocking the transition of G1-S in the cell cycle, thus, increasing the sensitivity to treatment - it has been established that cells located in late G1 and G2-M phases of the cell cycle are the most susceptible to ionizing radiation-induced cell death, whereas cells located in the S phase are the most resistant $[21,25]$. c) The drugs (for instance lovastatin) have been shown to affect the so called Bcl-2 family rheostat [26] decreasing expression of the antiapoptotic protein $\mathrm{Bcl}-2$ and increasing the expression of the proapoptotic protein Bax $[21,27,28]$.

d) Statins exhibitanti-angiogenic effects through down-regulation of pro-angiogenic factors, such as vascular endothelial growth factor, suppression of endothelial cell proliferation, and inhibition of adhesion to extracellular matrix by blocking intercellular adhesion molecules [22].

e) HMG-CoA reductase inhibitors affect cell signaling pathways associated with the invasive and metastatic properties of cancer cells $[21,27,29]$. For instance, lovastatin has been reported to decrease CYR61 (Cysteine-rich angiogenic inducer 6) expression resulting in suppressed osteosarcoma cell invasion and altered epithelial-to-mesenchymal-transition-related protein expression [30]. Simvastatin has been documented to downregulate the production of Matrix Metalloproteinase - 2 (MMP-2) [28].

f) Studies show that statins can interact additively or synergistically with some chemotherapeutic agents such as 5-fluorouracil, $\mathrm{N}, \mathrm{N}^{\prime}$ bis (2-choloroethyl)-N-nitrosourea, cisplatin, doxorubicin, and 1- $\beta$-d-arabinofuranosylcytosine [21]. A phase II study reported that simvastatin in combination with irinotecan/5-fluorouracil/leucovorin (FOLFIRI regimen) chemotherapy was effective and feasible with no additive sideeffects in patients with metastatic colorectal cancer [31].

g) The chemo-sensitizing [32,33] and radio-sensitizing [34] properties of statins have also been established.

h) The inhibition of the mevalonate pathway affects epigenetic regulation in cancer cells [35].

It has been shown that only lipophilic statins, such as simvastatin and lovastatin, show anticancer effect as they permeate the cell membrane [36-39].

The Antitumor Potential of Statins is Attractive for at Least Two Reasons: First, these drugs have been reported to possess anticancer properties against a wide variety of model systems in vitro and in vivo $[21,22,27,40]$; including cell cultures established from some of the most aggressive, lethal and socially important human malignancies for some of which currently there is limited number of treatment options, such as non-small cell lung cancer [41], triple negative breast cancer [28,42], pancreatic cancer $[27,43]$, osteosarcoma [44], and glioblastoma multiforme [40,45] Data shows that the combination of simvastatin and meclofenamic acid may be an effective strategy for the treatment of castrationresistant prostate cancer [46].

Second, the excessive cost and length of novelty drug discovery and development as well as the low rate of success motivates the repurposing of existing well-known and well-characterized (pharmacokinetics, pharmacodynamics, safety profile) non-cancer drugs for new application in oncology $[47,48]$. While antitumor activity of statins is widely reported in preclinical studies, the 
data on their anticancer efficacy in humans is controversial $[21,22,49,50]$. The recently published results from a meta-analysis of randomized controlled trials does not support clinical benefits of statins added to systemic anticancer therapy in patients with solid cancer [51].

Three main obstacles prevent successful clinical application of statins in cancer therapy:

a) These medications express their antitumor properties at relatively high doses (even 500 times higher than the ones used to treat hypercholesterolemia) that can induce serious side effects, including myopathy and rhabdomyolysis [52];

b) It is not possible to achieve such a high concentration of statins (upon oral intake) in the circulation because of their pharmacokinetic properties: short elimination half-lives (mostly $3 \mathrm{~h}$ or less) and low systemic bioavailability (below $20 \%$ ), with the exception of pitavastatin, due to an extensive first pass effect at the intestinal and/or hepatic level $[53,54]$. Therefore, the efforts of biomedical research are focused on creating different strategies to overcome these challenges. One of the most promising among them is to deliver statins as proliposomes or liposomes [55-59].

c) In addition, not all tumor cell lines / tumors are sensitive to statins that can contribute at least partially to the controversial results observed in clinical trials [60]. Reliable biomarkers are needed to predict sensitivity of tumors / patients to statin treatment. Transcriptome data from fourteen cancer cell lines and their statin concentration response data were used to prepare gene expression signatures able to identify statin sensitive and resistant cells. The validity of the identified biomarker profile was confirmed in additional experiments with an independent set of cell lines [61].

\section{Conclusion}

Statins are some of the most widely used medications in the world with significant input for primary and secondary prevention of cardiovascular diseases. The anticancer properties of these drugs have also been suggested and are attracting increasing interest among the biomedical society. However, further investigations are needed for an advanced clarification of the antitumor potential of statins (including particular cancer type(s), dosage and type of statin, treatment schedule and biomarkers to predict patient's sensitivity to this class of medications, etc).

\section{Acknowledgement}

The work was supported by Operational Programme "Science and Education for Smart Growth" 2014-2020, co-financed by the European Union through the European Structural and Investment Funds, Grant BG05M20P001-2.009-0019-C01 from 02.06.2017; National Science Fund, Bulgarian Ministry of Education and Science, Grant № ДКОСТ 01/16 from 17.08.2017; COST Action CA15135 "MuTaLig".

\section{References}

1. Endo A (2010) A historical perspective on the discovery of statins. Proc Jpn Acad Ser B Phys Biol Sci 86: 484-493.

2. Goldstein JL, Brown MS (1990) Regulation of the mevalonate pathway. Nature 343: 425-430.

3. Alberts AW (1988) Discovery, biochemistry and biology of lovastatin. Am J Cardiol 62: 10J-50J.

4. Endo A, Kuroda M (1976) Citrinin, an inhibitor of cholesterol synthesis. J Antibiot 29: 841-843.

5. Willey JZ, Elkind MS (2010) 3-Hydroxy-3-methylglutaryl-coenzyme A reductase inhibitors in the treatment of central nervous system diseases. Arch Neurol 67(9): 1062-1067.

6. (2015) GBD Risk Factors Collaborators (2016) Global, regional, and national comparative risk assessment of 79 behavioural, environmental and occupational, and metabolic risks or clusters of risks, 1990-2015: A systematic analysis for the Global Burden of Disease Study 2015. Lancet 388: 1659-1724.

7. Yusuf S, Hawken S, Ounpuu S, Dans T, Avezum A, et al. (2004) Effect of potentially modifiable risk factors associated with MI in 52 countries (the INTERHEART study): Case-control study. Lancet 364: 937-952.

8. Baigent C, Blackwell L, Emberson J, Holland LE, Reith C, et al. (2010) Efficacy and safety of more intensive lowering of LDL cholesterol: A meta-analysis of data from 170000 participants in 26 randomised trials. Lancet 376: 1670-1681.

9. Blaha MJ, Martin SS (2013) How do statins work? Changing paradigms with implications for statin allocation. J Am Coll Cardiol 62: 2392-2394.

10. Mihaylova B, Emberson J, Blackwell L, Keech A, Simes J, et al. (2012) The effects of lowering LDL cholesterol with statin therapy in people at low risk of vascular disease: Meta-analysis of individual data from 27 randomised trials. Lancet 380: 581-590.

11. Ridker PM, Danielson E, Fonseca FA, Genest J, Gotto AM, et al. (2008) Rosuvastatin to prevent vascular events in men and women with elevated C-reactive protein. N Engl J Med 359: 2195-2207.

12. Ramachandran R, Wierzbicki AS (2017) Statins, muscle disease and mitochondria. J Clin Med 6(8): 75.

13. Abd TT, Jacobson TA (2011) Statin-induced myopathy: a review and update. Expert Opin Drug Saf 10(3): 373-387.

14. Bouitbir J, Sanvee GM, Panajatovic MV, Singh F, Krähenbühl S (2019) Mechanisms of statin-associated skeletal muscle-associated symptoms. Pharmacol Res S1043-6618(19): 30011-30018.

15. Hilton-Jones D (2018) Statin-related myopathies. Pract Neurol 18(2): 97-105.

16. Ramkumar S, Raghunath A, Raghunath S (2016) Statin therapy: Review of safety and potential side effects. Acta Cardiol Sin 32(6): 631-639.

17. Furberg CD, B Pitt (2001) Withdrawal of cerivastatin from the world market. Curr Control Trials Cardiovasc 2: 205-207.

18. Cybulska B, Kłosiewicz-Latoszek L (2018) How do we know that statins are diabetogenic, and why? Is it an important issue in the clinical practice? Kardiol Pol 76(8): 1217-1223.

19. Thakker D, Nair S, Pagada A, Jamdade V, Malik A (2016) Statin use and the risk of developing diabetes: A network meta-analysis. Pharmacoepidemiol Drug Saf 25(10): 1131-1149.

20. Hoy SM (2017) Pitavastatin: A review in hypercholesterolemia. Am J Cardiovasc Drugs 17(2): 157-168.

21. Chan KK, Oza AM, Siu LL (2003) The statins as anticancer agents. Clin Cancer Res 9(1): 10-19. 
22. Vallianou NG, Kostantinou A, Kougias M, Kazazis C (2014) Statins and cancer. Anticancer Agents Med Chem 14(5): 706-712.

23. Casey PJ (1995) Protein lipidation in cell signaling. Science 268: 221225.

24. Ungefroren H, Witte D, Lehnert $H$ (2018) The role of small GTPases of the Rho/Rac family in TGF- $\beta$-induced EMT and cell motility in cancer. Dev Dyn 247(3): 451-461.

25. Fujiwara D, Tsubaki M, Takeda T, Tomonari Y, Koumoto YI, et al. (2017) Statins induce apoptosis through inhibition of Ras signaling pathways and enhancement of Bim and p27 expression in human hematopoietic tumor cells. Tumour Biol 39(10): 1010428317734947.

26. Volkmann N, Marassi FM, Newmeyer DD, Hanein D (2014) The rheostat in the membrane: BCL-2 family proteins and apoptosis. Cell Death Differ 21(2): 206-215.

27. Paškevičiūtè M, Petrikaitè V (2017) Differences of statin activity in 2D and 3D pancreatic cancer cell cultures. Drug Des Devel Ther 11: 32733280 .

28. Shen YY, Yuan Y, Du YY, Pan YY (2015) Molecular mechanism underlying the anticancer effect of simvastatin on MDA-MB-231 human breast cancer cells. Mol Med Rep 12(1): 623-630.

29. Warita K, Warita T, Beckwitt CH, Schurdak ME, Vazquez A, et al. (2014) Statin-induced mevalonate pathway inhibition attenuates the growth of mesenchymal-like cancer cells that lack functional E-cadherin mediated cell cohesion. Sci Rep 4: 7593.

30. Huang Y, Zhang J, Shao H, Liu J, Jin M, et al. (2018) miR-33a mediates the anti-tumor effect of lovastatin in osteosarcoma by targeting CYR61. Cell Physiol Biochem 51(2): 938-948.

31. Lee J, Jung KH, Park YS, Ahn JB, Shin SJ, et al. (2009) Simvastatin plus irinotecan, 5-fluorouracil, and leucovorin (FOLFIRI) as first-line chemotherapy in metastatic colorectal patients: A multicenter phase II study. Cancer Chemother. Pharmacol 64: 657-663.

32. Palko -Łabuz A, Środa-Pomianek K, Wesołowska O, Kostrzewa-Susłow E, Uryga A, et al. (2019) MDR reversal and pro-apoptotic effects of statins and statins combined with flavonoids in colon cancer cells. Biomed Pharmacother 109: 1511-1522.

33. Shojaei S, Alizadeh J, Thliveris J, Koleini N, Kardami E, et al. (2018) Statins: A new approach to combat temozolomide chemoresistance in glioblastoma. J Investig Med 66(8): 1083-1087.

34. Lee JY, Kim MS, Ju JE, Lee MS, Chung N, et al. (2018) Simvastatin enhances the radiosensitivity of p53 deficient cells via inhibition of mouse double minute 2 homolog. Int J Oncol 52(1): 211-218.

35. Karlic H, Thaler R, Gerner C, Grunt T, Proestling K, et al. (2015) Inhibition of the mevalonate pathway affects epigenetic regulation in cancer cells. Cancer Genet 208(5): 241-252.

36. Downs JR, Clearfield M, Weis S, Whitney E, Shapiro DR, et al. (1998) Primary prevention of acute coronary events with lovastatin in men and women with average cholesterol levels-Results of AFCAPS/TexCAPS. JAMA 279: 1615-1622.

37. Ghosh-Choudhury N, Charan Mandal C, Ghosh-Choudhury N, Ghosh Choudhury G (2010) Simvastatin induces depression of PTEN expression via NFkB to inhibit breast cancer cell growth. Cell Signal 22: 749-758.

38. Katz MS (2005) Therapy insight: Potential of statins for cancer chemoprevention and therapy. Nat Clin Pract Oncol 2: 82-89.

39. Pedersen TR, Wilhelmsen L, Faergeman O, Strandberg TE, Thorgeirsson G, et al. (2000) Follow-up study of patients randomized in the Scandinavian simvastatin survival study $(4 S)$ of cholesterol lowering. Am J Cardiol 86: 257-262.

40. Jiang P, Mukthavaram R, Chao Y, Nomura N, Bharati IS, et al. (2014) In vitro and in vivo anticancer effects of mevalonate pathway modulation on human cancer cells. Br J Cancer 111(8): 1562-1571.

41. Zhang X, Teng Y, Yang F, Wang M, Hong X, et al. (2015) MCM2 is a therapeutic target of lovastatin in human non-small cell lung carcinomas. Oncol Rep 33(5): 2599-2605.
42. Kou X, Jiang X, Liu H, Wang X, Sun F, et al. (2018) Simvastatin functions as a heat shock protein 90 inhibitor against triple-negative breast cancer Cancer Sci 109(10): 3272-3284.

43. Gong J, Sachdev E, Robbins LA, Lin E, Hendifar AE, et al. (2017) Statins and pancreatic cancer. Oncol Lett 13(3): 1035-1040.

44. Kany S, Woschek M, Kneip N, Sturm R, Kalbitz M, et al. (2018) Simvastatin exerts anticancer effects in osteosarcoma cell lines via geranylgeranylation and c-Jun activation. Int J Oncol 52(4): 1285-1294.

45. Bayat N, Ebrahimi-Barough S, Norouzi-Javidan A, Saberi H, Tajerian R, et al. (2016) Apoptotic effect of atorvastatin in glioblastoma spheroids tumor cultured in fibrin gel. Biomed Pharmacother 84: 1959-1966.

46. Sekine Y, Nakayama H, Miyazawa Y, Kato H, Furuya Y, et al. (2018) Simvastatin in combination with meclofenamic acid inhibits the proliferation and migration of human prostate cancer PC-3 cells via an AKR1C3 mechanism. Oncol Lett 15(3): 3167-3172.

47. Allison M (2012) NCATS launches drug repurposing program. Nature biotechnology 30: 571-572.

48. Deftereos SN, Andronis C, Friedla EJ, Persidis A, Persidis A (2011) Drug repurposing and adverse event prediction using high-throughput literature analysis, Wiley interdisciplinary reviews. Systems biology and medicine 3: 323-334.

49. Chae YK, Yousaf M, Malecek MK, Carneiro B, Chandra S, et al. (2015) Statins as anti-cancer therapy; Can we translate preclinical and epidemiologic data into clinical benefit? Discov Med 20(112): 413-427.

50. Zhong S, Zhang X, Chen L, Ma T, Tang J, et al. (2015) Statin use and mortality in cancer patients: Systematic review and meta-analysis of observational studies. Cancer Treat Rev 41: 554-567.

51. Jang HJ, Kim HS, Kim JH, Lee J (2018) The effect of statin added to systemic anticancer therapy: A Meta-analysis of randomized, controlled trials. J Clin Med 7(10). E325.

52. Hu M, Cheung BM, Tomlinson B (2015) Safety of statins: An update. Ther Adv Drug Saf 3: 133-144.

53. García MJ, Reinoso RF, Sánchez Navarro A, Prous JR (2003) Clinical pharmacokinetics of statins. Methods Find Exp Clin Pharmacol 25(6): 457-481.

54. Schachter M (2005) Chemical, pharmacokinetic and pharmacodynamic properties of statins: An update. Fundam Clin Pharmacol 19: 117-125.

55. Alupei MC, Licarete E, Patras L, Banciu M (2015) Liposomal simvastatin inhibits tumor growth via targeting tumor-associated macrophagesmediated oxidative stress. Cancer Lett 356: 946-952.

56. Matusewicz L, Podkalicka J, Sikorski AF (2018) Immunoliposomes with simvastatin as a potential therapeutic in treatment of breast cancer cells overexpressing HER2-an in vitro study. Cancers (Basel) 10(11). E418.

57. Safwat S, Ishak RA, Hathout RM, Mortada ND (2017) Statins anticancer targeted delivery systems: Re-purposing an old molecule. J Pharm Pharmacol 69(6): 613-624.

58. Sedki M, Khalil IA, El-Sherbiny IM (2018) Hybrid nanocarrier system for guiding and augmenting simvastatin cytotoxic activity against prostate cancer. Artif Cells Nanomed Biotechnol 46(sup3): S641-S650.

59. Yanamandra S, Venkatesan N, Kadajji VG, Wang Z, Issar M, et al. (2014) Proliposomes as a drug delivery system to decrease the hepatic firstpass metabolism: Case study using a model drug. Eur J Pharm Sci 64: 26-36.

60. Gazzerro P, Proto MC, Gangemi G, Malfitano AM, Ciaglia E, et al. (2012) Pharmacological actions of statins: a critical appraisal in the management of cancer. Pharmacological Rev 64: 102-146.

61. Raghu VK, Beckwitt CH, Warita K, Wells A, Benos PV, et al. (2018) Biomarker identification for statin sensitivity of cancer cell lines. Biochem Biophys Res Commun 495(1): 659-665. 


\section{ISSN: 2574-1241}

DOI: 10.26717/BJSTR.2019.17.002975

Radostina Alexandrova. Biomed J Sci \& Tech Res

(C) (i) This work is licensed under Creative

Submission Link: https://biomedres.us/submit-manuscript.php

$\begin{array}{ll}\text { BIOMEDICAL } & \text { Assets of Publishing with us } \\ \text { RESEARCHES } & \text { - Global archiving of articles } \\ & \text { - Immediate, unrestricted online access } \\ & \text { - Rigorous Peer Review Process } \\ \end{array}$

